\title{
La protección jurídico - penal de los miembros de la comunidad LGBTIQ en Cuba. Dinámica de cambio
}

\section{The Juridical Protection - Penal of the Members of the Community LGBTIQ in Cuba. Dynamics of Change}

Aymara Jarrosay Veranes* https://orcid.org/0000-0001-6718-2820 Juan Carlos Mendoza Pérez** https://orcid.org/0000-0003-3197-9605

Dalia Expósito Jerez ${ }^{* * *}$ https://orcid.org/0000-0001-6838-7350

* Magister Profesora Auxiliar de Derecho Penal General I y II en el Departamento de Derecho de la Universidad de Guantánamo, Cuba.

correo electrónico: aymarajv@cug.co.cu

** Magister, profesor Auxiliar de Derecho Civil y Derecho de Obligaciones en el Departamento de Derecho de la Universidad de Guantánamo, Cuba.

correo electrónico: jcperez@cug.co.cu; juanc1989@nauta.cu

*** Profesora Instructora en el Departamento de Derecho de la Universidad de

Guantánamo y jueza profesional de la Sesión de lo Penal del Tribunal Municipal Popular de Guantánamo, Cuba.

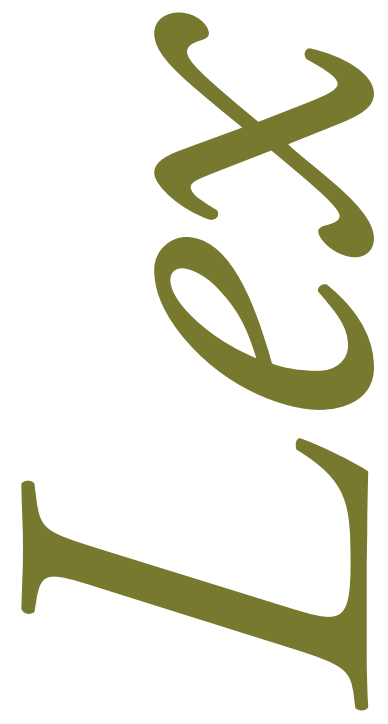




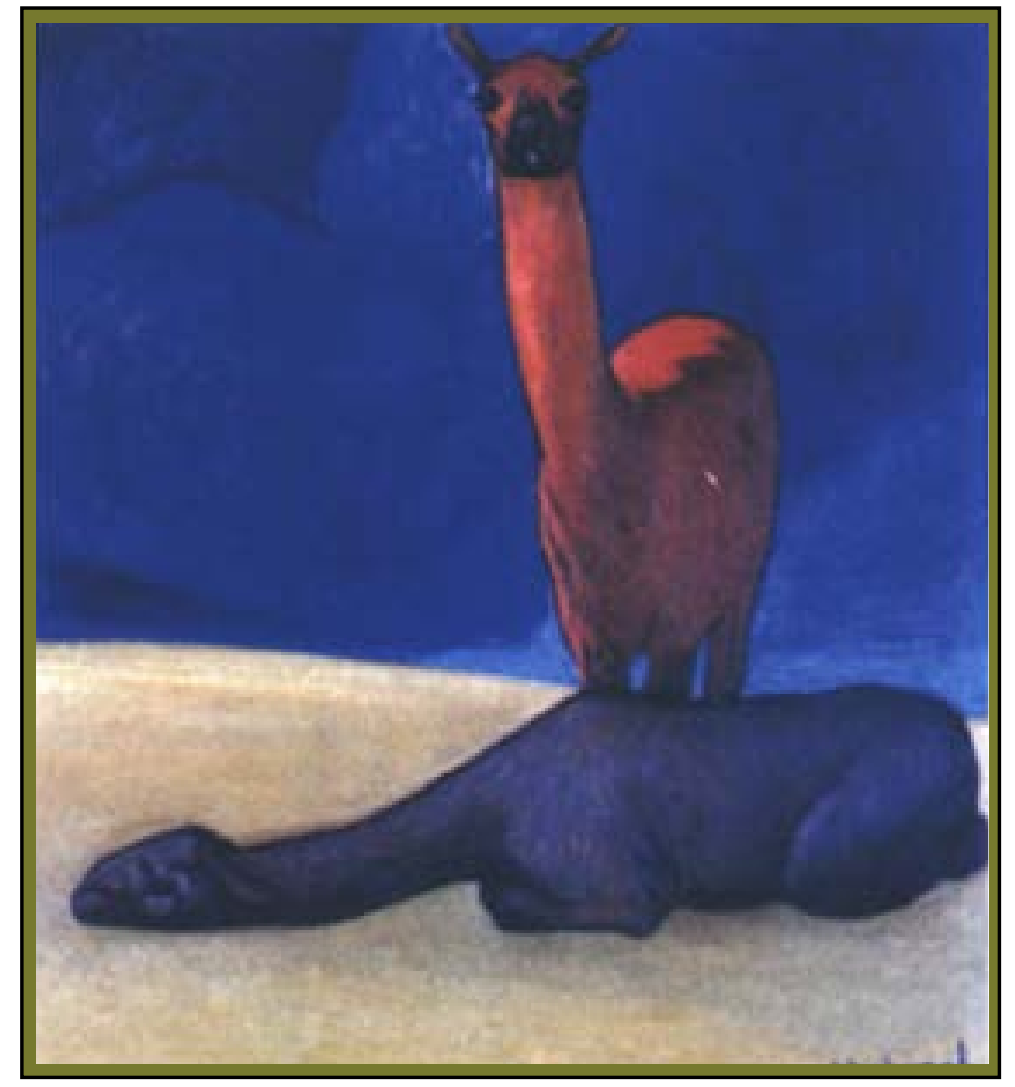

Las llamas. José Sabogal pintor peruano del indigenismo (Cajabamba-Cajamarca 1888-1957). 


\section{RESUMEN}

La presente investigación pretende diseñar a partir de un estudio doctrinal y exegético presupuestos teóricos y normativos para la configuración de los actos discriminatorios por razón de orientación sexual en la ley penal sustantiva cubana, lográndose con ello una mejor protección jurídica penal a los miembros de la comunidad LGBTIQ. A fin de cumplimentar los objetivos propuestos se emplearon métodos generales de las investigaciones teóricas: histórico-lógico, análisis-síntesis y el de inducción- deducción, métodos específicos de la investigación jurídica de orientación teórica como el teórico-jurídico, exegético-jurídico y jurídico-comparado; además del método empírico: análisis de contenido.

Palabras claves: actos discriminatorios, orientación sexual, miembros de la comunidad LGBTIQ, protección jurídica penal.

\section{ABSTRACT}

The present investigation seeks to design starting from a historical, doctrinal study and theoretical and normative presupposed exegetic for the configuration of the discriminatory acts for reason of sexual orientation in the law penal Cuban sustantiva, being achieved with it a better penal artificial protection to the members of the community LGBTIQ. In order to execute the proposed objectives general methods of the theoretical investigations they were used: historical-logical, analysis-synthesis and that of induction - deduction, specific methods of the artificial investigation of theoretical orientation as the theoretical-juridical, exegético-juridical and juridical-compared; besides the empiric method: content analysis.

Key words: discriminatory acts, sexual orientation, members of the community LGBTIQ, penal artificial protection. 
"Ni la existencia de leyes nacionales ni la prevalencia de las costumbres pueden de ninguna manera justificar los abusos, ataques, torturas e incluso asesinatos a las que las personas gays, lesbianas, bisexuales y transexuales están expuestas por quiénes son o cómo son percibidos (...) Este silencio infame es un rechazo inadmisible del principio fundamental de la universalidad de derechos."

\section{INTRODUCCIÓN}

La sociedad en la actualidad se caracteriza por ser cada día más heterogénea, con una inmensa diversidad en cuanto a estándares de vida, preferencias al vestir, niveles de educación, gustos por la música, pero hay un asunto que resulta ser muy llamativo en toda esa heterogeneidad, una cuestión que para unos es muy polémica por todo cuanto ello encierra, para otros un tema que ni siquiera debería ser abordado, lo que sí resulta ser un hecho es que para el mundo de hoy, independientemente de gustos y creencias se impone la necesidad de que se investigue y se le den respuestas a las interrogantes al respecto, ese asunto un tanto escabroso e incomprendido por algunas personas es el relacionado con la preferencia sexual y lo que ello implica desde el punto de vista jurídico.

El tema de la igualdad y la no discriminación de las lesbianas, los gays, bisexuales, transexuales e intersexuales trasciende las barreras nacionales para convertirse en asunto de análisis internacional. Disímiles son las personas que hoy sufren en el mundo el rechazo de sus amigos, familiares y la sociedad en general por mostrar una conducta sexual diferente a sus semejantes, para ellos convivir con el prejuicio y la discriminación de sus allegados ha constituido un difícil reto a superar, pero sin embargo, en el peor de los casos estas personas no reciben solo un maltrato psíquico sino que llegan a sufrir el maltrato y la violencia física, al punto de convertirse en víctimas de diferentes delitos por razón del prejuicio social.

A lo largo de los años estudiosos del asunto se han pronunciado por estudiar determinadas conductas relacionadas con la orientación sexual como es la Comisión Internacional de Juristas ${ }^{1}$ que desde el

1 La Comisión Internacional de Juristas (CIJ) es una organización no gubernamental dedicada a promover el conocimiento y el respeto del estado del derecho y la protección legal de los derechos humanos en todo el mundo. Su sede se encuentra en Ginebra, Suiza y cuenta con 37 secciones nacionales, 45 organizaciones afiliadas y 60 eminentes juristas 
principio de igualdad ante la ley defiende los derechos de esta comunidad y denuncian las arbitrariedades y crímenes de los cuales son objeto, ejemplificándolos desde las propias sentencias de tribunales ${ }^{2}$, como son las de la Corte Constitucional de Colombia en las cuales se ha apreciado una evolución en la protección de las personas que integran la comunidad de Lesbianas, Gay, Bisexual, Transexual e Intersexual $^{3}$, a partir de la distinción de conceptos como orientación sexual, condición sexual e identidad de género, tomando como base el respeto a la dignidad humana. También los investigadores del Centro de Estudios Derecho, Justicia y Sociedad -De justicia ${ }^{4}$ a solicitud de la Corte Constitucional colombiana presentaron una intervención ciudadana sobre la demanda de inconstitucionalidad instaurada por Eduardo Monte alegre Lynett contra el numeral 3 del artículo 58 y los artículos 134 y y 134 b de la Ley 599 de 2000, acusa a estas disposiciones legales de desconocer el principio de igualdad y de omisión legislativa, pues dentro de los elementos de los tipos penales de discriminación y hostigamiento y de la circunstancia de mayor punibilidad no contempla la identidad de género. A juicio del demandante, la ausencia de la identidad de género en las normas impide, en virtud del principio de legalidad, hacer imputaciones y reclamar la circunstancia de mayor punibilidad cuando hay actos de discriminación o violencia cometidos en contra de personas con identidad de género no normativa ${ }^{5}$. El demandante solicita que la Corte, mediante una sentencia integradora, resuelva el vacío en las disposiciones acusadas originada por la omisión legislativa relativa.

Por su parte la profesora Cristina Figueiredo Terezo de la Universidad Federal de Pará en Brasil, realizó una investigación sobre cómo los órganos del Sistema Interamericano de Derechos Humanos abordan el tema de la diversidad sexual, en la que se presenta la evolución normativa de la Organización de los Estados Americanos pasando por las resoluciones, hasta alcanzar los tratados interamericanos, para finalmente analizar las principales decisiones y recomendaciones de la Corte y de la Comisión Interamericana sobre el asunto ${ }^{6}$. Montserrat Comas d'Argemir magistrada presidenta de la $10^{a}$ Sección de la Audiencia Provincial de Barcelona aborda el asunto de los crímenes de odio entre otras razones por la orientación sexual pero de manera muy escueta.

de todas las regiones del mundo.

2 Sentencia T-569 de 1994, Corte Constitucional de Colombia, Sentencia T-477 de 1995, la Corte Constitucional hizo referencia al derecho a la identidad sexual como un presupuesto al derecho a la dignidad, En la C-481 de 1998, por su parte, comenzó a hacer una diferenciación entre la orientación sexual y lo que determinó como "identidad sexual" restrictivas, basadas en imprecisiones o ideas confusas que imperaban en aquél momento.

3 En lo adelante (LGTBIQ).

4 Marcela Sánchez Buitrago, Eliana Robles, Samuel Augusto Escobar Beltrán y Gustavo Adolfo Pérez, directora, abogada, abogado y antropólogo de Colombia Diversa, y César Rodríguez Garavito, Mauricio Albarracín Caballero, Paola Molano Ayala, Nina Chaparro González, Carlos Escoffié Duarte.

5 Se refiere aquella condición sexual LGBTI que no protege la norma.

6 Vid. Cristina Figuereido Terezo, Universidad de Pará, Brasil. Derechos Humanos y Diversidad Sexual en el sistema interamericano de protección de los Derechos Humanos, p. 379, disponible en http://repositorio.ciem.ucr.ac.cr/handle/123456789/271, consultado en fecha 13 de marzo. 
Por su parte el abogado colombiano Mauricio Noguera realiza un estudio sobre los crímenes de odio en América Latina, en el cual destaca los avances que ha habido al respecto, señalando algunos países que en ese sentido forman parte de esta avanzada, destacándose entre ellos Argentina, Chile, México y Colombia, los cuales, aunque no lo tipifiquen expresamente en su Código Penal sí tienen leyes antidiscriminación que contemplan agravantes para este tipo de violencia. Expresa el abogado que "El asunto en Colombia es que esta ley únicamente responde al odio, pero no al prejuicio que conduce a éste. No hay una solución estructural al problema" y explica como la sociedad influye muchas veces a estas actitudes agresivas asumidas por determinados ciudadanos, ese prejuicio acumulado por llamarlo de alguna manera y el contexto en el que ha vivido, conlleva a una acción agresiva, como respuesta a una educación recibida y a un aval social, cuando estos hechos quedan en la impunidad.

También el profesor Juan Alberto Díaz López de la Facultad de Derecho de la Universidad Autónoma De Madrid, España, en su tesis doctoral "El odio discriminatorio como circunstancia agravante de la responsabilidad penal", aborda la temática desde el enfoque de los crímenes de odio, resaltando entre otras categorías aquellos que son motivados por la orientación sexual o la identidad de género.

En cuanto al derecho patrio es importante destacar que las investigaciones que se han realizado analizan el asunto desde el enfoque psicosocial, en este sentido es de señalar que el tema objeto de investigación es liderado en nuestro país por el Centro Nacional de Educación Sexual (CENESEX) con su principal activista y directora la DRA. Mariela Castro Espín, quien entre otras obras ha publicado "La integración social de las personas transexuales en Cuba”, donde realiza un estudio sobre las categorías orientación sexual e identidad de género como constructos biomédico- normativos de la modernidad, que posteriormente han tenido desarrollos importantes en el campo de los derechos humanos ${ }^{7}$. De igual modo la publicación "Deconstruyendo mitos en torno a las parejas del mismo género y las familias homoparentales", de un colectivo de autores del CENESEX, es un material que pretende brindar algunos instrumentos para comprender la necesidad de ampliar la protección de los derechos de todas las personas, se contemplan varias de las características de las cuales se hacen mención en este trabajo ${ }^{8}$.

Por su parte el Manuel Vázquez Sejido, Subdirector del CENESEX y profesor de la Facultad de Derecho de la Universidad de La Habana, en su artículo "Derechos sexuales y violencia de género: algunas aproximaciones a la problemática de la violencia hacia personas LGBTI en Cuba" ${ }^{\text {, }}$ hace referencia a la discriminación que por motivo de su orientación sexual sufre este colectivo en nuestro país y en el mun-

7 Vid. Mariela Castro Espín, La integración social de las personas transexuales en Cuba, 2017, p.22. http://biblioteca. clacso.edu.ar/clacso/se/20191016033636/La_integracion_social_de_las_personas_transexuales.pdf.

8 Vid. Colectivo de Autores, CENESEX, "Deconstruyendo mitos en torno a las parejas del mismo género y las familias homoparentales", en Centro Nacional de Educación Sexual. https://www.ipscuba.net/media/2018/08/Folleto-Deconstruyendo-mitos.-23-de-julio-2018.pdf

9 Vid. Manuel Vázquez Seijido, "Derechos sexuales y violencia de género: algunas aproximaciones a la problemática de la violencia de género hacia personas LGBTI en Cuba”, Revista Sexología y Sociedad, Edit. Ciencias Médicas Volumen 23, No. 1 de 2017. http://revsexologiaysociedad.sld.cu/index.php/sexologiaysociedad/article/view/610 
do, resulta interesante resaltar el análisis que realiza en el ordenamiento jurídico cubano, destacando en este sentido un avance en el Código de Trabajo (Ley 116/2013) y señala como otra norma jurídica la Resolución 126 de 4 de junio de 2008 emitida por el Ministerio de Salud Pública ${ }^{10}$, instrumentos que de alguna manera han impulsado algunos mecanismos de promoción y defensa. Por otro lado, estudia la problemática desde el enfoque penalista, pero sin brindar una solución específica al problema actual.

Lo que resulta curioso de la bibliografía consultada es que se trata el tema desde el reconocimiento de derechos fundamentalmente constitucionales, pero aún así, la realidad y sensibilidad del asunto nos impone continuar profundizando en todo el ordenamiento jurídico de manera que se pueda ampliar la tutela de los derechos sexuales, principalmente y por ser el móvil de esta investigación, la protección desde el campo penal, sede en la que aún se ha incursionado muy poco en nuestro país y en la que resulta necesario propuestas concretas y objetivas, que ataquen el problema desde el punto de vista jurídico penal y brinden las herramientas de protección necesarias, lo que implica romper barreras y estereotipos sociales.

A pesar de que en Cuba no se genera una violencia de la magnitud que caracteriza al resto del mundo, es indudable que en nuestra sociedad sí se producen violaciones a los derechos de los LGBTIQ ${ }^{11}$. Lo expresado hasta aquí evidencia la insuficiente regulación jurídico penal de los actos socialmente peligrosos por razón de la orientación sexual.

Motivados por la actualidad del tema y el poco tratamiento dado en el ámbito doctrinal y legal, así como la necesidad de perfeccionar la norma sustantiva penal en cuanto a la protección jurídica de los actos discriminatorios por razón de orientación sexual en el país se traza la presente investigación cuyo objeto de estudio es la tutela jurídica de la orientación sexual, con un campo de acción que radica en la tutela jurídico penal de los actos discriminatorios por razón de orientación sexual a los miembros de la comunidad LGBTIQ en el ordenamiento jurídico cubano. En la que se pretende diseñar a partir de un estudio histórico, doctrinal, exegético y comparado, presupuestos teóricos y normativos para la configuración de los actos discriminatorios por razón de la orientación sexual en la ley penal sustantiva cubana, de modo que garantice una mejor protección jurídica penal a los miembros de la comunidad LGBTIQ.

10 Esta Resolución crea la Comisión Nacional de Atención Integral a Personas Transexuales (CNAIPT) y el Centro de Atención a la Salud Integral de las Personas Transexuales, con el objetivo básico de brindar servicios de salud integral que incluyen el estudio, tratamiento, investigación asistencial y seguimiento a las personas transexuales. En esta norma hallan garantía de orden material e institucional los derechos sexuales relativos a la libertad sexual, la autonomía, integridad y seguridad sexuales.

11 Cfr. Anexos 4 y 5. 


\section{IGUALDAD Y ORIENTACIÓN SEXUAL. ANÁLISIS DOCTRINAL}

Los principios pueden variar su contenido de acuerdo a la época y circunstancias históricas, en dependencia de los intereses y de lo que la sociedad en su conjunto puede considerar más valioso, de ahí que podemos decir que se van formando paulatinamente, es importante que se estudie brevemente el principio de la igualdad en el decursar del tiempo para una mayor comprensión de la dimensión que alcanza en la actualidad. La ideas ilustradas sobre la igualdad de todos los hombres habían sido cristalizadas en documentos insurgentes, de manera tal que como apuntara Maurizio Fioravanti las declaraciones revolucionarias de derechos suponen la victoria de la forma individualista frente al modelo historicista de fundamentar los derechos. ${ }^{12}$

El principio de igualdad realizado a través de la ley supone que los aplicadores de esta únicamente pueden sujetarse a las disposiciones de la legislación y no pueden ver más distinciones que las que previó la Asamblea, es decir, no existe otro punto de comparación distinto a la legislación pues:“(...) la ley ante la que todos los hombres son iguales es expresión de la voluntad general y por definición, a todos trata por igual. El principio de igualdad queda subsumido en el principio de la legalidad. Son iguales aquellos a quienes la ley considera como iguales y diferentes aquellos a quienes diferencia"13.

El movimiento constitucional del siglo XVIII que marcó el fin del Antiguo Régimen Francés, recogió las exigencias del principio de igualdad ante la ley. En este período se promulgó la Declaración de los Derechos del Hombre y el Ciudadano, adoptado por la Asamblea Constituyente Francesa, entre el 20 y el 26 de agosto de 1789, aceptada por el rey de Francia el 7 de octubre del mismo año que significó el fin de un estado de servidumbre y el acceso a la ciudadanía, reconociéndose algunos derechos humanos, entre ellos el de la igualdad, se establecían paulatinamente, las igualdades en diferentes ámbitos.

De forma textual en su artículo segundo planteaba el derecho a ser iguales al referir que "toda persona tiene los derechos y libertades proclamadas en esta declaración, sin distinción alguna de raza, color, sexo, idioma, religión, opinión política o de cualquier otra índole, origen nacional o social, posición económica, nacimiento o cualquier otra condición”. Esta declaración abrió paso a una nueva etapa en la vida del hombre, puesto que ya contaban con un instrumento jurídico que le respaldaría en la lucha por la defensa de sus derechos y que con el paso del tiempo ganó más terreno y se fue enriqueciendo hasta la actualidad. La igualdad se fundamenta constitucionalmente (todos los ciudadanos somos iguales ante la ley) sin embargo también en la propia usanza se hace necesario intervengan los poderes públicos ante el impedimento de una efectiva implementación debido a los criterios de discriminación que por variedad de motivos persisten en la sociedad.

12 Vid. Maurizio Fioravanti, Los derechos fundamentales, (Madrid, Trocca, 1996), p.35. https://ifc.dpz.es/recursos/publicaciones/17/99/13solisfernandez.pdf.

13 Vid. Francisco Rubio Llorente. La forma del poder (Estudios sobre la Constitución), Madrid, Centro de Estudios Constitucionales, 1993, 689 pág. 
Ahora bien, la igualdad se puede analizar desde dos facetas, la igualdad de trato y de interdicción de discriminación las cuales están muy relacionadas con los poderes públicos y se proyecta en dos planos diferentes: igualdad en la aplicación de la ley e igualdad en la ley ${ }^{14}$. La igualdad en la aplicación de la ley se refiere a que el operador jurídico debe hacer efectiva la aplicación de la norma de forma igual a toda aquella persona que haya realizado un hecho que se encuentre tipificado en la ley, sin que se haga diferencia en cuanto a las personas o circunstancias que no se encuentren presentes en la norma, poniéndose de manifiesto el principio de la legalidad y evitando una interpretación arbitraria del operador jurídico que pueda soslayar este principio. Al referirnos a la igualdad en la ley, debemos remitirnos al papel del legislador, o sea, el que legisla tiene la responsabilidad de no establecer diferencias entre iguales en casos donde las circunstancias de hecho coincidan, evitar criterios arbitrarios que traigan consecuencias jurídicas diferentes en casos con idénticas características.

Sin embargo, aun así no debemos perder de vista el principio de la proporcionalidad, recordemos entonces que el Derecho no es estático, la práctica nos enseña y demuestra que la vida es más rica que las normas, porque las condiciones y las circunstancias pueden variar, e incluso podemos hablar de normas específicas y normas genéricas. Existe otro análisis que debemos realizar sobre la igualdad relacionado a las posturas que adopta la doctrina y que se convierte en un debate contemporáneo, se suele hablar de la igualdad como un derecho fundamental teniendo en cuenta que es personal y la segunda con una tendencia a considerarla como un principio, si bien tenemos en cuenta que transversaliza todo el ordenamiento jurídico. La Igualdad es mucho más que un derecho, es por tanto, la premisa de todos los derechos y la atmósfera que hace posible su ejercicio real y efectivo ${ }^{15}$. La igualdad, en tanto derecho subjetivo, es un principio de no discriminación, ya que se prohíbe cualquier diferencia de trato en el ejercicio de derechos y libertades. Así ha quedado reiterado en innumerables ocasiones por la jurisprudencia española ${ }^{16}$.

Si el principio de igualdad implica que todas las personas son iguales ante la ley más allá de sus cualidades físicas, gustos y preferencias, la discriminación constituye una violación a este principio y más allá, a la dignidad humana, teniendo en cuenta que esta última está estrechamente relacionada al concepto de igualdad. El hecho de no reconocer a una persona derechos que son semejantes a los del

14 Vid. Rodrigo Pérez Lisicic; Reflexiones en torno a la igualdad y discriminación: la STC 13/2001 como pretexto, en Derecho constitucional para el siglo XXI: actas del VIII Congreso Iberoamericano de Derecho Constitucional / coord. por Manuel Carrasco Durán, Francisco Javier Pérez Royo, Joaquín Urías Martínez, Manuel José Terol Becerra, Vol. 1, 2006, ISBN 84-9767-692-0, págs. 887-912, disponible en https://dialnet.unirioja.es/servlet/articulo?codigo=2228334, consultado en fecha 13 de marzo de 2020.

15 Vid. Javier Pérez Royo, Curso de Derecho Constitucional, ISBN 9788491231523, Editorial Marcial Pons, Ediciones Jurídicas y Sociales, Edición 16, 2018, p. 154. Madrid, España. https://www.marcialpons.es/libros/curso-de-derecho-constitucional/9788491235613/.

16 V.gr. En la Sentencia 75/83 el Tribunal Constitucional español lo ha dejado sentado: (...) "El principio de igualdad sólo resulta vulnerado cuando dicha diferencia de trato esté desprovista de una justificación objetiva y razonable, es decir, cuando es discriminatoria”. 
resto conlleva inevitablemente a una limitación de sus libertades del mismo modo que restringe su derecho a disfrutar de una vida digna.

En cuanto a la discriminación se pueden tener en cuenta diferentes acepciones, todas coinciden de manera general en el trato diferencial o cualquier forma de exclusión, distinción o restricción hacia una persona o grupo de personas con base en ciertas características incidentales (color de la piel, religión, sexo, etc. $)^{17}$. O sea, es toda acción de separar, aislar o excluir a una persona por sus características inherentes de un grupo social determinado, lo cual según la línea de nuestra investigación constituye una violación de sus derechos.

La discriminación tiene los orígenes de su surgimiento en el llamado estigma, el cual se puede definir como el proceso que se desarrolla de forma dinámica y que conlleva a la desvalorización del individuo de forma tal que queda desacreditado frente al resto de la sociedad, por lo cual es fácil de inferir que coloca a las personas en un estado de baja autoestima en muchos de los casos, cuando esta se conforma aparece lo que conocemos como la discriminación. Algunas de las personas que pertenecen a la comunidad LGBTI generalmente cuando se sienten rechazados y apartados en la sociedad presentan lo que se conoce como la auto discriminación y son estigmatizadas.

Las sociedades se caracterizan por presentar una gran diversidad dentro de sí mismas, numerosas son las culturas que se unen para dar origen a una nueva, cada grupo etario tiene sus gustos y necesidades, cada grupo social por sí solo crea sus propios cánones, retos y desafíos, resta entonces evaluar si existe igualdad en ellos. La comunidad LGBTI como es conocida por sus siglas en español es la comunidad lesbiana, gay, bisexual, transexual e intersexual y a ella pertenecen todas aquellas personas cuya orientación sexual está dirigida al gusto por aquellos individuos de su mismo sexo o de ambos sexos.

La homosexualidad es una orientación sexual y se define como la interacción o atracción sexual, afectiva, emocional y sentimental hacia individuos del mismo sexo, incluido el lesbianismo, en la actualidad se le denomina homosexual a la persona gay, o sea, al hombre que sienta atracción por otro hombre, por su parte el lesbianismo lo manifiesta la mujer que mantiene una relación sexual y sentimental con otra mujer, nos preguntamos entonces ¿¿ónde está la diferencia? La respuesta está en el origen etimológico de la palabra. Etimológicamente, la palabra homosexual es un híbrido del griego homos (que en realidad significa «igual» y no, como podría creerse, derivado del sustantivo latino homo, «hombre») y del adjetivo latino sexualis ${ }^{18}$. Es necesario antes de adentrarnos a este complejo mundo de la comunidad LGBTI conocer en qué consisten estos calificativos.

17 Cfr. Manuel Osorio, Diccionario de Ciencias Jurídicas, Políticas y Sociales, (Guatemala:1ra. Edición electrónica, Datascan S.A.), se define la discriminación como aquella "acción y efecto de discriminar, de separar, distinguir una cosa de otra. Desde el punto de vista social, significa dar trato de inferioridad a una persona o colectividad por motivos raciales, religiosos, políticos u otros.

18 Vid. Diccionario de la Real Academia de la Lengua Española, Edición 22da., disponible en https: //dle.rae.es/?id=KbVHzwk, consultado en fecha 8 de noviembre de 2018. 
Sexo: Características físicas del cuerpo (tanto genotípico como fenotípico), de manera que, según el sexo, las personas se identifican como masculinos, femeninos e intersexuales ${ }^{19}$. Género: Construcción cultural del sexo, es decir, los roles sociales atribuidos a los hombres y mujeres ${ }^{20}$. Heterosexual: Hombre o mujer cuyo deseo afectivo y sexual está dirigido a personas que se identifican con un sexo/género distinto al mío ${ }^{21}$. Orientación Sexual: Se refiere a la capacidad de cada persona de sentir una profunda atracción emocional, afectiva y sexual por personas de un género diferente al suyo o de su mismo género, o de más de un género, así como la capacidad de mantener relaciones íntimas y sexuales con estas personas. ${ }^{22}$ Identidad de Género: Se refiere a la vivencia interna e individual del género tal como cada persona la siente profundamente, la cual podría corresponder o no con el sexo asignado al momento del nacimiento, incluyendo la vivencia personal del cuerpo, que podría involucrar la modificación de la apariencia o la función corporal a través de medios médicos, quirúrgicos o de otra índole, siempre que la misma se escoja libremente, y otras expresiones de género que incluyan la vestimenta, el modo de hablar y los modales ${ }^{23}$.

Lesbiana: Mujer cuyo deseo afectivo y sexual está dirigido hacia otras mujeres ${ }^{24}$. Gay: Hombre cuyo deseo afectivo y sexual está dirigido hacia otros hombres ${ }^{25}$. Bisexual: Hombre o mujer cuyo deseo sexual y afectivo está dirigido tanto a personas del mismo sexo/género como a personas que se identifican con un sexo/género distinto ${ }^{26}$. Transgénero: Hombre o mujer que transita entre lo masculino y femenino de forma permanente o transitoria ${ }^{27}$. Intersexual: Una persona intersexual nace con una anatomía sexual, órganos reproductivos o patrones cromosómicos que no se ajustan a la definición típica del hombre o de la mujer. Esto puede ser aparente al nacer o llegar a serlo con los ańos. Puede identificarse como hombre o como mujer o como ninguna de las dos cosas. La condición de intersexual no tiene que ver con la orientación sexual o la identidad de género: las personas intersexuales experimentan la misma gama de orientaciones sexuales e identidades de género que las personas que no $\operatorname{lo~son}^{28}$. Transexual: Aquella persona cuyo sexo anatómico de nacimiento no concuerda con su sexo psicológico (o identidad sexual) y que, por este motivo, adopta una serie de estrategias encaminadas hacia la adecuación física de

\section{9 Ídem}

20 Ibídem

21 Ibídem

22 Vid. Principios de Yogyakarta, (2006), p.8. Disponible en http://yogyakartaprinciples.org/principles-sp/about/, consultado en fecha 21 de noviembre de 2019.

23 Ídem

24 Vid. Libres e Iguales. Naciones Unidas." La protección internacional de las personas LGBTI", México, octubre de 2014, p.6, disponible en www.ohchr.org www.unfe.org, consultado en fecha 8 de noviembre de 2020.

25 Ídem

26 Ibídem

27 Ibídem

28 Ibídem 
su sexo psicológico. Con este objetivo la persona hará lo posible por iniciar un proceso de tratamiento hormonal y a menudo también quirúrgico conocido como proceso transexualizador ${ }^{29}$.

Es evidente que la propia comunidad internacional se ha encargado de señalar sus propias diferencias e ir formando las bases para el reclamo de sus derechos, dentro de este grupo tan diverso de personas con diferentes gustos y preferencias cada cual ocupa una posición, o eres gay, o eres lesbiana, lo que puede traducirse como eres hombre o eres mujer, la expresión puede resultar redundante ciertamente, pero un análisis del asunto con una mirada desde la igualdad nos indica entonces que existe una marcada diversidad en la propia comunidad, es como decir que ante el mundo nos unimos para luchar por nuestros derechos y todos somos iguales, sin embargo a lo interno cada cual es libre para elegir su modo de actuación.

La denominación de una persona como lesbiana, gay, bisexual, transgénero o intersex (LGBTIQ) asegura el reconocimiento legal de la orientación sexual o de la identidad de género como condición esencial de la persona a ser protegida. La noción de LGBTI como un sector específico permite visibilizar y reconocer la discriminación histórica a la que han estado sometidas las personas que se encuentran en este supuesto, contribuyendo a ofrecer protección acorde a sus necesidades particulares. Cabe señalar que una persona con una orientación sexual o identidad de género diversa no necesariamente deberá de auto identificarse bajo la denominación LGBTI para ser acreedora de protección.

Está ampliamente documentado que en todas las regiones del mundo las personas LGBTI son blanco de homicidios, violencia sexual y de género, agresiones físicas, maltrato y tortura, detenciones arbitrarias, acusaciones de conducta inmoral, "desviada" o "antinatural", y de limitación, restricción o exclusión en goce de los derechos de reunión, de expresión y de información, entre otros. Igualmente, dichas personas son discriminadas en el acceso a derechos sociales como el derecho al empleo, al más alto nivel posible de salud y a la educación. La discriminación que sufren las personas por su orientación sexual o identidad de género se manifiesta como la distinción, exclusión, restricción, o preferencia no justificada que tiene por objeto o por resultado, anular o menoscabar el reconocimiento, goce o ejercicio, en condiciones de igualdad, de sus derechos y libertades. La discriminación que sufren las personas LGBTIQ está profundamente enraizada y alimentada por prejuicios, estereotipos sociales y culturales y por información distorsionada o imprecisa, aunado a la existencia de doctrinas de la sociología, la medicina, el derecho y la política que han originado o justificado dicha discriminación.

En muchos casos la violencia y los actos discriminatorios son tan graves que terminan forzando su desplazamiento a otros países como única opción para proteger sus derechos, en particular el derecho a formular y seguir su proyecto de vida de acuerdo a su identidad y orientación sin miedo. Desafortunadamente, las personas LGBTIQ no siempre logran conseguir protección internacional bajo la figura

29 Vid. Principios de Yogyakarta, (2006), p.8. Disponible en http://yogyakartaprinciples.org/principles-sp/about/, consultado en fecha 21 de noviembre de 2019. 
del asilo u otras formas de protección internacional. Muchas veces los sistemas de asilo no garantizan la capacitación ni la imparcialidad de los funcionarios quienes operan bajo prejuicios de género, ni son sensibles a las particularidades y necesidades de la población LGBTIQ.

Hasta aquí el estudio realizado en la doctrina foránea ha mostrado que la igualdad puede ser vista tanto como principio, así como un derecho, los elementos que anteriormente fueron abordados permiten ratificar este criterio, es un derecho que posee la persona de forma individual que le permite vivir y disfrutar de una forma plena y es a su vez el principio que informa a todo el ordenamiento jurídico a partir del cual se rigen el resto de las normas. Es por ello que cualquier forma de discriminación basada sobre todo en la orientación sexual, constituye una violación al principio fundamental de universalidad de los derechos.

\section{HOMOFOBIA O PREJUICIO POR LA ORIENTACIÓN SEXUAL MÁS ALLÁ DE UNA DISTINCIÓN ETIMOLÓGICA}

Sin lugar a dudas la discriminación que sufren las personas LGBTIQ los coloca como uno de los sectores más vulnerables de una sociedad en la que rige la heteronormatividad y la que se niega aceptar la existencia de un tercer sexo o sexo neutro. Es por ello que se apela a la llamada homofobia para justificar este pensamiento en pleno siglo XXI. El término homofobia hace referencia a la aversión (fobia, del griego antiguo fobos, "pánico") obsesiva contra hombres o mujeres homosexuales, aunque generalmente también se incluyen a las demás personas que integran la diversidad sexual, como es el caso de las personas bisexuales o transexuales, y las que mantienen actitudes o hábitos comúnmente asociados al otro sexo, como los metrosexuales y los hombres con ademanes tenidos por femeniles o las mujeres con ademanes tenidos por varoniles ${ }^{30}$.

Entre las mejores y más explicitas definiciones sobre este vocablo se encontró a la homofobia como la aversión a los homosexuales y se manifiesta de diversas formas. Es un miedo irracional hacia personas homosexuales tanto hombres como mujeres ${ }^{31}$. Muchas veces se cree que no existe gente homosexual en los círculos sociales y sin saber se comparte a diario con estas personas, pero por el hecho de no saber que lo son, no se les da ninguna importancia; por lo tanto no se presenta ninguna conducta de rechazo hacia ellos. La homofobia ha sido la causante de muchas situaciones tristes y lamentables como es el rompimiento en relaciones familiares, laborales, suicidios y asesinatos.

30 Vid. Diccionario de la Real Academia de la Lengua Española, Edición 22da., disponible en https: //dle.rae.es/?id=KbVHzwk, consultado en fecha 22 de enero de 2020.

31 Cfr. Bruquetas Castro, Fernando. Outing En España: Los Españoles Salen Del Armario (Spanish Edition) (Español) Tapa blanda - 1 Enero 2001. Editorial: H.M.R. ISBN-10: 8492343362; ISBN-13: 978-8492343362, disponible en https://www.amazon.com/-/es/Fernando-Bruquetas-Castro/dp/8492343362. 
La homosexualidad dentro de la esfera familiar es concebida como pecado, defecto o enfermedad y esto da como resultado una homofobia en la sociedad ${ }^{32}$. Pero el punto es si es miedo a una persona con gusto sexual por el mismo sexo o el miedo a poder aceptar o reconocer que ellos también tienen esa misma inclinación. La homofobia representa un cambio significativo en los puntos de vista respecto a la homosexualidad, lo complejo del asunto es que las actitudes homofóbicas se consideren como el problema relevante, más que la homosexualidad misma.

La homofobia como constructo se valida por estudios conductuales, en los cuales se han medido respuestas somáticas equivalentes de las fobias (respuesta cardiaca, por ejemplo) en personas intolerantes con los homosexuales. En sentido estricto, una fobia es el temor irracional. En el caso de la homofobia, su rango es variado, incluye el odio, el señalamiento del homosexual como contrario, inferior o anormal y, en el caso del discurso psiquiátrico, el hecho de ubicarlo en el rango patológico o sintomático ${ }^{33}$. Una forma sutil de homofobia es considerar la homosexualidad como "opción o elección" y no como orientación sexual; una forma más agresiva la constituye el equiparar el homosexualismo con la psicosis o el trastorno de la personalidad ${ }^{34}$.

En la actualidad se identifican varios tipos de homofobia ${ }^{35}$ :

a) Homofobia personal. Consiste en un sistema personal de creencias tales como sentir compasión por la incapacidad de los homosexuales de controlar sus deseos, odio por considerarlos psicológicamente trastornados, genéticamente defectuosos o inadaptados cuya existencia contradice las leyes de la naturaleza, espiritualmente inmorales, infectados, asquerosos o inferiores a los heterosexuales.

b) Homofobia interpersonal. Afecta las relaciones entre los individuos, por ejemplo, poner apodos o hacer chistes, agredir física o verbalmente, retirar apoyos y rechazar a la persona.

c) Homofobia institucional. Formas en que organismos gubernamentales, educativos o religiosos discriminan sistemáticamente, por ejemplo a través de leyes y su aplicación.

d) Homofobia cultural. Se refiere a normas sociales o códigos de conducta que, sin estar expresamente inscritos en una ley o reglamento, funcionan en la sociedad para legitimar la opresión.

Por su parte el término prejuicio (del latín praeiudicium, "juzgado de antemano”) distante etimo-

32 Cfr. Harold Shetemul, "Mayas homofóbicos", en Revista electrónica de discusión y propuesta social, Año 2 - 2005. Disponible en http://www.albedrio.org/htm/articulos/s/shetemul-034.htm.

33 Vid. Ricardo Espirella Guerrero, "Homofobia y Psiquiatría”, Revista Colombiana de Psiquiatría, Vol XXXVI, No.4, (2007), p.7, disponible en https:/www.redalyc.or. Consultado el 22 de marzo de 2020.

34 Vid. M. Nieves Quiles del Castillo, et al, "La medida de la homofobia manifiesta y sutil”, Revista Psicothema, vol. 15, núm. 2, (2003): p 14, Oviedo, España, disponible en. www.redalyc.org, consultado el 22 de marzo de 2020

35 Colectivo de autores, Homofobia y masculinidad, p.13, disponible en https:/www.redalyc.or, consultado el 22 de marzo de 2020. 
lógicamente del vocablo homofobia, pero unidos por la realidad social, es el proceso de formación de un concepto o juicio sobre alguna cosa de forma anticipada. En términos psicológicos, es una actividad mental inconsciente que distorsiona la percepción ${ }^{36}$.

Otros autores definen el prejuicio como una actitud suspicaz y hostil hacia una persona que pertenece a un grupo, por el simple hecho de pertenecer a dicho grupo, y a la que, a partir de esta pertenencia, se le presumen las mismas cualidades negativas que se adscriben a todo el grupo ${ }^{37}$. En esta definición hace referencia principalmente al instinto del ser humano de etiquetar negativamente sobre la base de una forma de pensar que adquirimos desde las primeras edades, influenciado por la educación, principios y valores que la familia, la escuela y la sociedad en general inculcan al individuo, la necesidad de prejuzgar, emitir una opinión aún sin tener certeza de esa supuesta verdad.

El prejuicio no nace con las personas sino más bien es aprendido ${ }^{38}$ en la escuela de la vida y son precisamente los estereotipos sociales los que hacen a las personas prejuiciosas, ese modelo de vida en el cual se imprime la heteronormatividad y la masculinidad, negando de tal modo la dignidad humana individual, reconociéndose además que el individuo lo usa según su conveniencia. En las prácticas cotidianas de los sujetos opera sobre la base de los juicios valorativos basados en las costumbres, tradiciones y el proceso de formación y consolidación de las culturas y las identidades.

Hasta aquí se ha podido evidenciar como sin lugar a dudas la homofobia y el prejuicio por la orientación sexual son dos constructos sociales que atacan directamente el libre desenvolvimiento de la personalidad de los miembros del colectivo LGBTIQ, empleando para ello desde las formas más sutiles hasta las más crueles, la situación puede pasar de simples chistes, bromas, risas, hasta los golpes, torturas y los más horribles asesinatos. De esta manera llegan a configurarse los actos discriminatorios cuya gravedad conlleva a los llamados crímenes de odio o crímenes por prejuicio ${ }^{39}$. La imposición del orden de la mayoría, que niega la diferencia y no reconoce la complejidad de las relaciones humanas puede ser tan cruel como capaz de tolerar la violencia ${ }^{40}$. Desde el Derecho corresponde ofrecer dirección y evidencia jurídica del daño que provoca la exclusión y corresponde desarrollar propuestas coherentes de normativas que permitan la protección y la tutela judicial efectiva de las personas víctimas de este fenómeno.

36 Vid. Diccionario de la Real Academia de la Lengua Española, Edición 22da., disponible en https: //dle.rae.es/?id=KbVHzwk, consultado en fecha 22 de enero de 2020.

37 Vid. Gordon W. Allport, The Nature of Prejudice, en Estados Unidos: 25 Anniversary Edition, 1954, p.39.

38 Ídem.

39 Crímenes de odio: acto doloso generalmente realizado con saña, que incluye, pero no se limita a: violaciones del derecho a la vida, integridad personal, libertad personal; el cual tiene la intención de causar daños graves o muerte a la víctima, basando la agresión en el rechazo, intolerancia, desprecio, odio y/o discriminación hacia un grupo en situación de vulnerabilidad, en este caso siendo este grupo la población LGBTIQ en general y sus integrantes. Tomado de: http:// www.oas.org/es/cidh/LGBTI/estudios/. Orientación sexual, identidad de género y expresión de género: algunos términos y estándares relevantes.

40 Tomado de El estado actual de la investigación sobre la discriminación sexual, disponible en www.conicyti.cl, consultado el 22 de marzo de 2020. 


\section{ANÁLISIS DE LA PROTECCIÓN A LA ORIENTACIÓN SEXUAL EN EL ORDENAMIENTO JURÍDICO PENAL CUBANO. PROPUESTAS PARA SU PERFECCIONAMIENTO}

Con el triunfo de la Revolución Cubana en 1959 y el avance y consolidación del proceso revolucionario cubano, ha tenido lugar un proyecto de justicia y equidad social comprendido por un conjunto de transformaciones sociales y culturales que se traducen en la erosión del patriarcado como paradigma del poder. Como parte de este proceso se han reconocido un grupo importante de derechos humanos vinculados a la sexualidad de las personas. El derecho a la educación sexual en las diferentes etapas de la vida del individuo, el acceso a servicios de salud relacionados con las decisiones reproductivas, entre otros ejemplos son evidencias de los pasos de avance en Cuba.

Sin embargo, al realizarse un análisis objetivo de la legislación cubana vigente, es fácil percatarse que a pesar de los esfuerzos por encaminar jurídicamente esta situación y la voluntad política del Estado, aún existe desprotección a los derechos sexuales relacionados con la orientación sexual y la identidad de género. La práctica ha demostrado que existe una insuficiente protección jurídica de las personas LGBTI frente a la ocurrencia de actos de violencia por razón de su orientación sexual, este ha resultado uno de los temas sobre la mesa en los debates actuales ${ }^{41}$, sobre todo en un momento trascendental para el país como es la actualización del ordenamiento jurídico y como resultado de las discusiones populares en el marco de la consulta de la nueva Constitución de la República, la que arrojó la necesidad de consagrar los derechos sexuales de la diversidad en el texto constitucional, atemperando a Cuba al resto del mundo y ofreciéndole una seguridad jurídica a quienes han catalogado de diferentes.

Es necesario entonces y constituye un reclamo del colectivo LGBTIQ, dirigir la mirada sobre las principales expresiones de violencia hacia personas con orientaciones sexuales e identidades de género no heteronormativas, así como sistematizar la información al respecto, pueden ser estos algunos de los fundamentos para avanzar en este complejo pero no imposible camino hacia la protección de los derechos sexuales en el contexto cubano. El nuevo texto constitucional cubano, aprobado el 24 de febrero de 2019, a diferencia del anterior refrenda algunos derechos sexuales en los artículos $42,43,44,46,47,48$, los que expresan la igualdad de todos los ciudadanos ante la ley, recibiendo la mis-

41 En los momentos actuales el reclamo por los derechos de los LGBTI se ha fortalecido y ha encontrado respaldo institucional, a su vez ha venido dando los primeros pasos desde el punto de vista legal, vale destacar entonces en Cuba, la creación del Centro Nacional de Educación Sexual (CENESEX), la Comisión Nacional de Atención Integral de las Personas Transexuales (CNAIPT), el Centro de Atención a la Salud Integral de las Personas Transexuales, los diferentes eventos científicos en los que se exponen los temas relacionados con el, género, la violencia de género, la jornada de lucha contra la homofobia, instituyéndose de manera oficial el 17 de mayo como el día de lucha contra la homofobia, todo lo cual ha impulsado la voluntad del Estado de respaldar jurídicamente a este colectivo de personas, desde el punto de vista legal la primera norma que salió a la luz refrendado la protección de la orientación sexual fue el Código de Trabajo en su artículo segundo, pero más reciente aún fueron los debates populares de lo que fue el proyecto constitucional, devenido hoy en Constitución de la República, cuyos artículos referidos a los derechos sexuales y la orientación sexual aportaron más del $24 \%$ de la propuestas e intervenciones. 
ma protección y oportunidades, garantizan precisamente el derecho a no sufrir discriminación entre otras razones por la orientación sexual, hacen alusión a la responsabilidad del Estado en garantizar la igualdad de sus ciudadanos y el respeto a este principio, por su parte el 47 y el 48 aluden al libre desenvolvimiento de la personalidad siempre guardando el debido respeto a la sociedad, garantizándose de este modo el disfrute del derecho a la libertad sexual y a participar en la vida pública, por supuesto con el límite del respeto al derecho ajeno, lo que precisa el precepto número 45, refiriéndose a mantener el orden público, la seguridad colectiva y el bienestar general, pareciera este artículo hacer un llamado a la conciencia de todos los ciudadanos y no solo de aquellos que por las propias trabas sociales hoy exigen el libre desarrollo de su personalidad, aduciendo fundamentalmente a mantener las buenas costumbres sociales. Precisamente partiendo de estos postulados es posible ampliar el camino hacia la protección de los LGBTI.

También en la Ley Fundamental cubana pueden ser identificadas algunas de las garantías a estos derechos en los preceptos 92, 97, 98 y 99, responsabilizando al Estado con la misión de garantizar a través de las normas el acceso a la justicia de todos los ciudadanos ante la vulneración de sus derechos y su protección con una tutela judicial efectiva de sus derechos, es de resaltar como en el artículo 97 los ciudadanos pueden acceder a sus datos personales, a los registros públicos y solicitar su rectificación o modificación, lo cual con una interpretación amplia, aseguraría otros derechos sexuales, abriendo la posibilidad a rectificar la identidad del individuo de acuerdo a su orientación sexual, sobre todo luego de aplicarse algún tratamiento médico quirúrgico como la reasignación de sexo.

Dentro de estas garantías también se encuentra la posibilidad de reclamar ante los tribunales la restitución de algún derecho vulnerado por entidades o funcionarios estatales, vale destacar que los miembros de esta comunidad a menudo son rechazados e incluso revictimizados al acudir ante algún ente estatal o no estatal, esto podría implícitamente llevar una respuesta en sede penal de ser configurados al igual que en otros países, los actos discriminatorios en el Código penal cubano. De modo que al ser este un precepto que requiere de una posterior norma de desarrollo, en la nueva ley que se dicte pueda ser reconocido este derecho para la comunidad LGBTI, asegurando su acceso a esta oportunidad de litigar ante la justicia efectiva y transparente de los tribunales.

En el ordenamiento jurídico cubano no se reconocen todos los derechos sexuales vinculados a la orientación sexual y la identidad de género, puede hacerse mención a la regulación de algunos de estos derechos en la Resolución 126 de 4 de junio de 2008, del Ministerio de Salud Pública, la cual crea la Comisión Nacional de Atención Integral a Personas Transexuales (CNAIPT) y el Centro de Atención a la Salud Integral de las Personas Transexuales, con el objetivo básico de brindar servicios de salud integral que incluyen el estudio, tratamiento, investigación asistencial y seguimiento a las personas transexuales. En esta norma hallan garantía de orden material e institucional los derechos sexuales relativos a la libertad sexual, la autonomía, integridad y seguridad sexuales, así como la educación y la atención de salud sexuales de forma universal y gratuita. 
Otra de estas normas es la Ley 116 de 2013, Código de Trabajo, la que en su artículo 2 relativo a la igualdad incorpora dentro de su regulación la no discriminación por orientación sexual en este ámbito. Sin embargo, en el resto de las normativas ni en su reglamento se hace mención alguna sobre este particular, situación esta que propicia que aún hoy se continúen presentando casos de discriminación en el acceso al empleo en Cuba, fundamentalmente para los transexuales a los cuales constantemente se les vulnera este derecho por la nueva identidad que asumen según su orientación sexual.

Con respecto a la norma jurídica penal vigente en Cuba, se puede mencionar que uno de sus objetivos es la promoción de "la cabal observancia de los derechos y deberes de los ciudadanos". En este sentido se advierte cómo los bienes jurídicos protegidos a través de la concepción de tipos penales coinciden con los contenidos de algunos de los derechos sexuales, aunque no se haga alusión taxativamente. Es necesario entonces mencionar el artículo 295.1, este tipo penal regula el delito contra el derecho de igualdad, sancionando la conducta discriminatoria hacia otra persona o que promueva o incite a la discriminación, ya sea con manifestaciones y ánimo ofensivo a su sexo, raza, color, origen nacional o con acciones para obstaculizarle o impedirle por estos motivos, el ejercicio o disfrute de los derechos de igualdad establecidos en la Constitución de la República. Sin lugar a dudas esta regulación actual no le brinda una efectiva protección a los LGBTIQ, en primer lugar porque ya se encuentra desfasada con respecto a la nueva Constitución, que sí regula dentro de las categorías proscritas la orientación sexual en su precepto dirigido a la igualdad, en un segundo momento este precepto de la ley penal cubana es de los menos invocados partiendo también a veces del propio desconocimiento jurídico de las víctimas como consecuencia del propio rechazo social al que constantemente son sometidos.

De igual manera, la ley penal sustantiva cubana, sanciona otras conductas que protegen bienes jurídicos superiores que pudiesen garantizar el disfrute del derecho a la libertad sexual, así como a la autonomía, la integridad y seguridad sexuales, como es el caso de los delitos contra la vida y la integridad corporal a partir del artículo 261 y siguientes del Código Penal. También se pueden encontrar en el Título IX de los delitos contra los derechos individuales contenidos del artículo 279.1 al 286.1. Por otra parte los delitos contra el normal desarrollo de las relaciones sexuales y contra la familia, la infancia y la juventud, regulados del artículo 298.1 al 310.1 pudiesen garantizar estos derechos.

No obstante, la forma en que se encuentran regulados, hace que los hechos que se cometen con una base discriminatoria sean sancionados como delitos comunes, y en el peor de los casos al no existir una clara mención por parte del legislador y quedar a la libre interpretación del operador jurídico, quien aún no ha logrado una conciencia en este sentido, pueden quedar impunes o pasar por desapercibidas acciones u omisiones socialmente peligrosas que vulneran un valor supremo para el ser humano, como es el respeto y protección a la orientación sexual y que dicha vulneración es una conducta lesiva a la dignidad humana, a la cual el Estado debía agregarle valor punitivo para que garantice verdaderamente ese libre desenvolvimiento de la personalidad y el derecho a la integridad física y moral, a las que hacen referencia los artículos 46 y 47 de la Carta Magna de Cuba. 
También puede suceder que la orientación sexual influya en la valoración que se realice en el momento de determinar la responsabilidad penal de personas que hayan ejercido violencia sobre otras por este motivo, llegando a darse casos donde existan conductas que justifiquen el actuar sancionado o que incluso aleguen la no existencia de normas específicas para casos de ese tipo. Igual sucede en los casos donde la orientación sexual de personas que cometen delitos pueda tenerse en cuenta menoscabando los derechos que les asisten, o sea la vulneración se manifiesta cuando son víctimas, pero también al ser los autores o responsables de una acción delictiva.

La práctica muestra que no son aplicados determinados elementos previstos en el Código Penal cubano que pudieran resultar útiles en el tratamiento a las diferentes manifestaciones de violencia, y en particular aquellas ejercidas por razón de la orientación sexual de las personas. En este sentido se puede citar la sanción accesoria de prohibición de frecuentar lugares determinados, prevista en el artículo 41.1, la cual puede aplicarse cuando existan fundadas razones para presumir que la presencia del sancionado en determinados lugares puede generar que cometa otros delitos. La sugerencia estaría dirigida a poder explotar un poco más esta posibilidad que brinda el Código con esta sanción accesoria y ser más empleada en las sentencias y fallos de los tribunales. De manera que los órganos correspondientes de la Policía Nacional Revolucionaria pudiesen con una cabal observancia prevenir la reincidencia de la comisión de acciones socialmente peligrosas que menoscaben el pleno ejercicio de los derechos del colectivo LGBTIQ.

De manera similar puede observarse el denominado estado de peligrosidad, regulado en el artículo 73.1, el cual se aprecia cuando concurren ciertos índices de peligrosidad, entre estos la conducta antisocial. El estado peligroso por conducta antisocial se describe en el artículo 73.2 como el quebrantamiento habitual de las reglas de convivencia social mediante actos de violencia y otros que puedan lesionar los derechos de los demás, disponiéndose en el artículo 80.1 el internamiento del sujeto declarado en tal sentido en un establecimiento especializado por un período de hasta 4 años, y en el 81.1, la posibilidad de que sea su conducta vigilada y controlada por los órganos de la Dirección General de la Policía Nacional Revolucionaria. En muchas ocasiones los miembros de la comunidad LGBTIQ son víctimas de constantes actos discriminatorios cometidos por sujetos conocidos, sin embargo, no acuden a las estaciones de la PNR por temor a ser rediscriminados, y por ello, estas personas no son denunciadas, o advertidas y por ende, no se les aplica todo lo relativo al estado peligroso por conducta antisocial.

Es justo mencionar también algunos de los elementos que han tributado e impulsado el andar en este sentido, de modo que los documentos rectores del trabajo del Partido Comunista de Cuba (PCC), han tributado de manera significativa, como lo es el objetivo número 57 de su Primera Conferencia Nacional como resultado de las amplias discusiones, referido al enfrentamiento de los prejuicios y conductas discriminatorias entre otras razones por la orientación sexual, lo cual sería contrario a la Constitución y las leyes, limitando el ejercicio de los derechos de las personas. Posteriormente en su $7 \mathrm{mo}$ Congreso, el PCC reconoció también el principio de no discriminación como elemento fundamental en el desarrollo social del país, y definió como una de las características principales del ideal de sociedad 
socialista la igualdad de derechos y sus garantías, sobre la base de la equidad, inclusión, justicia social y el enfrentamiento a toda forma de discriminación motivada por cualquier distinción lesiva a la dignidad humana, incluyendo el género, la orientación sexual y la identidad de género ${ }^{42}$.

Por otra parte en una entrevista ${ }^{43}$ realizada a los especialistas, coordinadores y promotores de la Sección Provincial del Programa ITS-VIH-SIDA y Hepatitis B y C, de la Vice dirección del Centro Provincial de Higiene y Epidemiología, que atienden los programas sobre los LGBTI, se pudo constatar que hasta el momento el principal apoyo que reciben los miembros de esta comunidad, proviene del Centro Nacional de Educación Sexual (CENESEX), cuyo departamento jurídico se encarga de tramitar las quejas y preocupaciones de estas personas ${ }^{44}$.

Según informes de los Servicios de Orientación Jurídica del Centro Nacional de Educación Sexual $(\mathrm{SOJ})^{45}$ desde años anteriores al 2007 se registraron casos recibidos en la institución, ya que este servicio conecta, como especie de bisagra, los conflictos y problemáticas recibidos con la institución estatal en cuyo ámbito de actuación se encuentra la solución o parte de esta. La dinámica de atención generada a partir del desarrollo de este servicio ha permitido identificar las problemáticas fundamentales asociadas al reconocimiento y garantía de los derechos sexuales como derechos humanos, las principales violaciones y el desarrollo de estrategias de atención para lograr soluciones a los diferentes conflictos tratados.

Los datos relativos a los casos recibidos dan cuenta de un aumento considerable en estas radicaciones. Durante los años 2013 y 2014 se atendieron 1360 casos, lo que contrasta con los 2198 casos atendidos durante 2015 y 2016. Según el informe de balance de trabajo desarrollado por el Grupo Asesor Jurídico del CENESEX, en 2016 fueron atendidos 355 casos en los espacios de consulta establecidos y 714 recibidos por correspondencia. Un número importante de personas denunciaron casos de discriminación por orientación sexual e identidad de género en el ámbito laboral y familiar, advirtiéndose vulneración de derechos a partir de estas situaciones de discriminación.

Las principales manifestaciones de discriminación ${ }^{46}$ provienen del rechazo de la sociedad, eventos de discriminación en el ámbito comunitario, pero a ello se une la actuación de los órganos de la Policía

42 Cfr. Conceptualización del modelo económico y social cubano de desarrollo socialista y Plan nacional de desarrollo económico y social hasta 2030: propuesta de visión de la nación, ejes y sectores estratégicos, documentos del 7mo Congreso del Partido Comunista de Cuba, celebrado del 16 al 19 de abril de 2016, disponible en http://www.cubadebate.cu, consultado en fecha 12 de abril de 2020.

43 Ver anexos 2 y 3.

44 A pesar de la existencia de otros mecanismos de atención directa a todo ciudadano, las personas LGBTI acuden en mayor medida a este centro en busca de respuestas y apoyo para sus diferentes situaciones, al declarar sentirse mejor atendidos y con un nivel de respuesta satisfactorio. Este centro se encarga de viabilizar las principales preocupaciones mediante los mecanismos y canales institucionales creados al efecto.

45 Estos servicios funcionan desde el año 2007 como un espacio para la atención, orientación y acompañamiento de personas cuyos derechos sexuales han resultado vulnerados por disímiles eventos.

46 Ver Anexo 4. 
Nacional Revolucionaria, la cual frecuentemente discrimina a este colectivo imponiéndoles sobre todo multas por deambular en las noches, horario nocturno que ha sido escogido por estas personas para socializar, puesto que durante el día la situación es más compleja por el propio prejuicio de la sociedad, más aún tratándose de los transexuales. Estos últimos los más afectados y a los que continuamente le son vulnerados sus derechos por su condición. Según sus propias declaraciones el acceso al trabajo de este grupo de personas es más difícil, ya que al crearse una nueva identidad por su orientación sexual, la cual en la mayoría de los casos no ha sido reconocida legalmente, le niegan la posibilidad de empleo en muchos lugares, aún cuando se trata de profesionales y personas capacitadas, en última instancia solo pueden acceder a un puesto de auxiliar de limpieza, violando de este modo la Constitución de la República y el Código de Trabajo ${ }^{47}$.

La situación se torna más compleja cuando la mirada se vuelve más crítica, aún cuando en los últimos años se ha venido trabajando en función de concientizar a toda la población y educarlos en el respeto a la orientación sexual de cada cual, la violencia generada en los últimos años continúa cobrando víctimas, dejando como saldo fallecidos y lesionados, entre ellos transexuales, Hombres que tienen Sexo con otros Hombres (HSH), Personas que Practican Sexo Transaccional (PPST) y Personas que Viven con VIH (PVV) ${ }^{48}$, muchos de los cuales han sido producto de la violencia por motivos prejuiciosos. Afirman los especialistas que se vuelve muy difícil demostrar que es el prejuicio el principal móvil que impulsa a cometer el delito ${ }^{49}$, sobre todo porque se deben mantener al margen de la investigación y generalmente los juicios se realizan a puertas cerradas. Eso sin dejar de mencionar que en muchas ocasiones cuando son amenazados o sufren algún tipo de lesión que proceden a realizar la denuncia, son maltratados en el órgano correspondiente y no reciben una respuesta, sino que la denuncia resulta archivada.

Sin lugar a dudas los mecanismos con los que se cuenta hoy no son los más efectivos para la protección de este colectivo, aún cuando el CENESEX y la CNAIPT (Comisión Nacional de Atención Integral a personas Transexuales) trabajan para fomentar la educación sexual y el respeto al derecho ajeno a definirse sexualmente, existen otros problemas que se escapan de sus manos y que el legislador debe responder desde una posición penalista. A pesar de la existencia de estas posibles herramientas a aplicar, la realidad indica que son insuficientes y que el momento exige de mecanismos o fórmulas directamente aplicables para la efectiva protección de la comunidad LGBTIQ, porque dejándolo del

47 Incluso ha habido casos de estudiantes de la Facultad de Ciencias Médicas de Guantánamo que por su condición de transexuales han sido expulsados del centro de estudios, remitiéndose quejas al departamento jurídico del CENESEX para su análisis.

48 Información ofrecida por la Sección Provincial del Programa ITS-VIH-SIDA y Hepatitis B y C, de la Vice dirección del Centro Provincial de Higiene y Epidemiología.

49 En un intercambio con jueces del Tribunal Provincial de Guantánamo se constató que no se conocen de hechos contra personas LGBTI en los que se haya tomado en consideración en la sanción, como móvil para cometer el delito, el prejuicio por la orientación sexual. 
modo en que se encuentra en la actualidad todo dependería de la interpretación que haga el operador del Derecho, la que puede favorecer o no a la víctima y al no existir alusiones directas, la cuestión dependería de la subjetividad.

Es por ello que basados en los resultados de esta investigación se proponen los siguientes presupuestos teóricos y normativos que pueden contribuir al perfeccionamiento del ordenamiento jurídico penal cubano:

1. Los Actos Discriminatorios por orientación sexual constituyen toda acción prejuiciosa que indique rechazo hacia una persona o grupo de personas, impidiéndole arbitrariamente, obstruyéndole o restringiéndole el pleno ejercicio de sus derechos por su inclinación afectiva, emocional y sexual hacia otra u otras de un género diferente al suyo, o de su mismo género, o de más de un género, así como a la capacidad de mantener relaciones íntimas y sexuales con estas personas.

2. El delito por prejuicio es toda acción u omisión socialmente peligrosa motivada por una actitud hostil, intolerante, discriminatoria, de desprecio y de rechazo, hacia una persona o grupo de personas en situación de vulnerabilidad, en el caso específico, los LGBTIQ, provocándoles entre otras, violaciones del derecho a la vida, a la integridad personal, a la libertad personal, con la intención de causarles dańos graves e incluso la muerte.

3. Que en virtud de la garantía refrendada en el artículo 99 de la Constitución de la República, referida al acceso a los tribunales de los ciudadanos ante la vulneración de alguno de sus derechos, expresados en dicha Ley Fundamental, y como parte de la norma de desarrollo que el mencionado precepto indica, sea tomado en consideración como uno de esos derechos, los sexuales, específicamente los que protejan la orientación sexual para el libre desenvolvimiento de la personalidad y el pleno goce de sus derechos, garantizándoles de este modo el acceso de los miembros de la comunidad LGBTIQ a una tutela judicial efectiva.

4. Que, en la ley penal cubana, en su Libro I, Parte General, Título XI, en el artículo 53, circunstancias agravantes, se conciba la discriminación por orientación sexual como agravante.

5. Tomando como punto de partida la entrada en vigor de una nueva Constitución, en la que se regula en el artículo 42 dirigido a la igualdad la orientación sexual, se propone evaluar la inclusión de esta categoría dentro del delito contra el derecho de igualdad, del artículo 295.1 del Código Penal cubano.

6. Partiendo del estudio del derecho comparado y del análisis de la protección jurídico penal de la comunidad LGBTIQ en el ordenamiento cubano, es posible proyectar un tipo penal específico que regule los actos discriminatorios basados en la orientación sexual y tomando como referencia el concepto de delito por prejuicio. 


\section{CONCLUSIONES}

En el ordenamiento jurídico cubano no aparecen refrendados todos los derechos sexuales. La nueva Constitución de la República incluye la categoría orientación sexual en el artículo 42, abriendo la posibilidad de ampliar los derechos y sus garantías. Con ello, la protección en el Código Penal que hasta ahora ha sido insuficiente puede tomar un giro interesante a favor de las víctimas LGBTI.

$\mathrm{Al}$ no existir preceptos legales que hagan alusiones directas y solo dejando a la libre interpretación del operador del Derecho la aplicación del artículo 295.1 del Código Penal u otras variantes dentro del propio código, puede ser que los hechos que se cometan sean sancionados como delitos comunes o en el peor de los casos quedar impunes o pasar por desapercibidos, aún constituyendo acciones $\mathrm{u}$ omisiones socialmente peligrosas.

Resulta una cuestión científicamente ostensible el que los derechos sexuales son derechos humanos. El reconocimiento de aquellos que se encuentran vinculados con la orientación sexual y las garantías para su ejercicio, es tarea pendiente para el ordenamiento jurídico penal cubano, es por ello que se presenta una propuesta de presupuestos teóricos y normativos que se considera puedan contribuir a su perfeccionamiento.

\section{REFRENCIAS}

- Álvarez, Javier Teodoro. Crímenes de odio contra las disidencias sexuales: concepto, orígenes, marco jurídico nacional e internacional. Disponible en https://www.palermo.edu/derecho/revista_juridica/pub-16/Revista_Juridica_Ano16-N1_03. pdf, consultado en fecha 12 de febrero de 2019.

- Álvarez-Icaza L. Emilio. et al, Violencia contra personas lesbianas, gay, bisexuales, trans e intersex en América. Comisión Interamericana de Derechos Humanos, 2015, disponible en www.cidh.og, consultado en fecha 22 de marzo de 2019.

- $\quad$ Allport Gordon W. The Nature of Prejudice. Estados Unidos: 25th Anniversary Edition, 1954.

- Aranda Álvarez, Elviro, "Discriminación por razón de sexo en el ámbito político: los problemas de las cuotas electorales", en PÉREZ ROYO, Javier et al (coord.), Derecho constitucional para el siglo XXI: Actas del VII Congreso Iberoamericano de Derecho Constitucional, vol. 1, Navarra: Aranzadi, 2006, pp. 771-796.

- Becerra Gelover, Alejandro. Atención a la discriminación en Iberoamérica. Un recuento inicial, disponible en www.redalic.or, consultado en fecha 22 de marzo de 2019.

- Bruquetas Castro, Fernando. Outing En España: Los Españoles Salen Del Armario (Spanish Edition) (Español) Tapa blanda - 1 Enero 2001. Editorial: H.M.R. ISBN-10: 8492343362; ISBN-13: 978-8492343362, disponible en https://www.amazon.com/-/es/Fernando-Bruquetas-Castro/dp/8492343362. 
- Castro Espín, Mariela. La integración social de las personas transexuales en Cuba, 2017, p.22. disponible en http://biblioteca.clacso.edu.ar/clacso/se/20191016033636/La_integra cion_social_de_las_personas_transexuales.pdf.

- Colectivo de Autores, CENESEX, "Deconstruyendo mitos en torno a las parejas del mismo género y las familias homoparentales", en Centro Nacional de Educación Sexual. https://www.ipscuba.net/media/2018/08/Folleto-Deconstruyendo-mitos.-23-de-julio2018.pdf

- Constitución de la República de Cuba de 24 de febrero de 1976, reformada en 1992 y 2002, Gaceta Oficial Extraordinaria No. 3 de 31 de enero de 2003.

- Constitución de la República de Cuba del 24 de febrero de 2019, disponible en www.cubadebate.cu, consultado en fecha 12 de abril de 2020.

- Declaración Universal de Derechos Humanos, promulgada y aprobada por la Asamblea General de las Naciones Unidas el 10 de diciembre de 1948, disponible en: http://www.un.org/es/documents/udhr/, consultado en fecha 10 de enero de 2019.

- Declaración sobre orientación sexual e identidad de género de las Naciones Unidas, disponible en https://www.uv.mx/uge/files/2014/05/Declaracion-Sobre-OrtientacionSexual-e-Identidad-de-Genero-de-las-Naciones-Unidas.pdf, Consultado en fecha 13 de marzo de 2019.

- Diccionario de la Real Academia de la Lengua Española, Edición 22da., disponible en https: //dle.rae.es/?id=KbVHzwk, consultado en fecha 22 de enero de 2020.

- $\quad$ Figuereido Terezo, Cristina. Derechos Humanos y Diversidad Sexual en el sistema interamericano de protección de los Derechos Humanos. Universidad de Pará, Brasil: p. 379, disponible en http://repositorio.ciem.ucr.ac.cr/handle/123456789/271, consultado en fecha 13 de marzo.-Fioravanti, Maurizio. Los derechos fundamentales. Madrid: Trocca, 1996, p.35. https://ifc.dpz.es/recursos/publicaciones/17/99/13solisfernandez.pdf

- Guerrero, Ricardo Espirella. "Homofobia y Psiquiatría”, Revista Colombiana de Psiquiatría, Vol XXXVI, No.4, 2007, p.7, disponible en https:/www.redalyc.or. Consultado el 22 de marzo de 2020.

- Ley 116 de 2013, Código de Trabajo de la República de Cuba, disponible en www.cubadebate.cu, consultado en fecha 10 de octubre de 2019.

- $\quad$ Ley 62 de 1987, Código Penal de la República de Cuba, disponible en www.parlamentocubano.cu, consultado en fecha 10 de octubre de 2020.

- Osorio; Manuel. Diccionario de Ciencias Juridicas, Politicas y Sociales, Guatemala: 1 ra. Edición electrónica, Datascan S.A. 
- Oviedo, Gabriela. La homosexualidad en Cuba. Entrevista a Mariela Castro Espín, Buenos Aires, Argentina, disponible en www.cubadebate.cu, consultado en fecha15 de noviembre de 2018.

- $\quad$ Pérez Lisicic, Rodrigo. "Reflexiones en torno a la igualdad y discriminación: la STC 13/2001 como pretexto". Derecho constitucional para el siglo XXI: actas del VIII Congreso Iberoamericano de Derecho Constitucional / coord. por Manuel Carrasco Durán, Francisco Javier Pérez Royo, Joaquín Urías Martínez, Manuel José Terol Becerra, Vol. 1, 2006, ISBN 84-9767-692-0, págs. 887-912, disponible en https://dialnet.unirioja.es/ servlet/articulo?codigo=2228334, consultado en fecha 13 de marzo de 2020

- Pérez Royo, Javier. Curso de Derecho Constitucional, ISBN 9788491231523, Editorial Marcial Pons, Ediciones Jurídicas y Sociales, Edición 16, 2018, p. 154. Madrid, España. https://www.marcialpons.es/libros/curso-de-derecho-constitucional/9788491235613/.

- Principios de Yogyakarta, (2006), p.8. Disponible en http://yogyakartaprinciples.org/ principles-sp/about/, consultado en fecha 21 de noviembre de 2019.

- Quiles del Castillo, M. Nieves, et al, "La medida de la homofobia manifiesta y sutil", Revista Psicothema, vol. 15, núm. 2, (2003). p 14, Oviedo, España, disponible en. www.redalyc.org, consultado el 22 de marzo de 2020.

- $\quad$ Resolución 126 del 4 de junio de 2008 del Ministerio de Salud Pública, disponible en www.sld.cu, consultado en fecha 12 de abril de 2020.

- Rubio Llorente., Francisco. La forma del poder (Estudios sobre la Constitución), Madrid, Centro de Estudios Constitucionales, 1993, 689 pág.

- Shetemul, Harold, "Mayas homofóbicos”, en Revista electrónica de discusión y propuesta social, Año 2 - 2005. Disponible en http://www.albedrio.org/htm/articulos/s/shetemul-034.htm.

- Vázquez Seijido, Manuel. "Derechos sexuales y violencia de género: algunas aproximaciones a la problemática de la violencia hacia personas LGBTI en Cuba”. Revista Sexología y Sociedad, Edit. Ciencias Médicas Volumen 23, No. 1 de 2017. p. 76.

http://revsexologiaysociedad.sld.cu/index.php/sexologiaysociedad/article/view/610

RECIBIDO: 08/02/2021

APROBADO: $15 / 05 / 2021$ 


\section{ANEXOS}

\section{ANEXO 1: Derecho Comparado.}

En Colombia el principio de igualdad está establecido en Artículo 13o de la Constitución:

Todas las personas nacen libres e iguales ante la ley, recibirán la misma protección y trato de las autoridades y gozarán de los mismos derechos, libertades y oportunidades sin ninguna discriminación por razones de sexo, raza, origen nacional o familiar, lengua, religión, opinión política o filosófica. El Estado promoverá las condiciones para que la igualdad sea real y efectiva y adoptará medidas en favor de grupos discriminados o marginados.

El Estado protegerá especialmente a aquellas personas que por su condición económica, física o mental, se encuentren en circunstancia de debilidad manifiesta y sancionará los abusos o maltratos que contra ellas se cometan.

En Colombia numerosos han sido los casos de violencia contra personas homosexuales, trans o intersex, utilizada como un mecanismo para reprocharle o negarle su identidad de género o tratar de cambiarle a "la fuerza" su orientación sexual.

De entrada, lo anterior significa que ya estas formas de discriminación y violencia hacen parte del ámbito de protección demarcado por el derecho penal. No obstante, a continuación, se evidenciará cómo esto se ha enfatizado en desarrollos jurisprudenciales y legales que, igualmente, permiten sostener que este ordenamiento jurídico ha adoptado un modelo nuevo en torno a la discriminación. La Corte Constitucional en sentencia C-671 de 2014 afirmó que existen diferentes modelos de discriminación, señaló que el tipo de discriminación que ataca la ley 1482 son aquellos que se relacionan con los "crímenes de odio", en los que el patrón de la conducta son los sentimientos de hostilidad, rechazo y animadversión" 50

Entonces, de acuerdo a la Corte Constitucional, el tipo de discriminación que ataca la ley 1482 tiene las siguientes características con respecto a los elementos previamente señalados:

1) Respecto al origen, este debe ser personal y no institucional

2) En cuanto al patrón señala que es la hostilidad, el odio o la animadversión contra el colectivo o los individuos parte de él

3) La forma se caracteriza por discursos y actos inequívocos de ataques y exclusión

4) En relación con la notoriedad, la Corte señala que la ley 1482 castiga las formas más visibles y notorias de discriminación, no aquellas "sutiles e invisibles"

50 Corte Constitucional de Colombia, sentencia C-671/2014. M.P Luis Guillermo Guerrero. Parr. 7.6.2 
5) En cuanto a la intencionalidad la ley sanciona los actos claros e inequívocos en razón de criterios sospechosos o prohibidos de discriminación

6) Se dirige contra los actos que afectan a poblaciones conformadas en función de una condición específica sin desconocer las particularidades de las discriminaciones que se pueden producir por las interseccionalidades.

En Argentina el principio de igualdad ante la ley está reconocido en el artículo 16 de la Constitución

La Nación Argentina no admite prerrogativas de sangre, ni de nacimiento: No hay en ella fueros personales ni títulos de nobleza. Todos sus habitantes son iguales ante la ley, y admisibles en los empleos sin otra condición que la idoneidad. La igualdad es la base del impuesto y de las cargas públicas.

En Nicaragua, Artículo 27 de la Constitución, ley máxima de la nación:

Todas las personas son iguales ante la ley y tienen derecho a igual protección. No habrá discriminación por motivos de nacimiento, nacionalidad, credo político, raza, sexo, idioma, religión, opinión, origen, posición económica o condición social. Los extranjeros tienen los mismos deberes y derechos que los nicaragüenses, con la excepción de los derechos políticos y los que establezcan las leyes; no pueden intervenir en los asuntos políticos del país. El Estado respeta y garantiza los derechos reconocidos en la presente Constitución a todas las personas que se encuentren en su territorio y estén sujetas a su jurisdicción.

En España, Artículo 14 de la Constitución:

Los españoles son iguales ante la ley, sin que pueda prevalecer discriminación alguna por razón de nacimiento, raza, sexo, religión, opinión o cualquiera otra condición o circunstancia personal o social.

A continuación, se señalan las novedades más significativas en relación a la reforma del Código Penal en cuanto al tema que se aborda:

Entre las circunstancias del artículo 22.4 se distinguen orientación sexual, identidad sexual y razones de género. Estos mismos términos se incorporan al artículo 510 entre las razones que pueden dar lugar a actuaciones "de odio" o "discriminatorias" 51 . Se modifica la muy debatida redacción del artículo 510, de manera que se precisa mucho más el tipo de actuación que se considera como "delito de odio":

1) "Serán castigados con una pena de prisión de uno a cuatro años y multa de seis a doce meses...

a) "Quienes públicamente fomenten, promuevan o inciten directa o indirectamente al odio, hostili-

51 Los motivos que literalmente contempla el Código Penal en este tipo de delitos son, junto a las señaladas, los racistas, antisemitas u otros referentes a la ideología, religión o creencias, situación familiar, la pertenencia sus miembros a una etnia, raza o nación, su origen nacional, enfermedad o discapacidad. 
dad, discriminación o violencia contra un grupo, una parte del mismo, o contra una persona determinada por razón de su pertenencia a aquél...”

b) "Quienes produzcan, elaboren, posean con la finalidad de distribuir, faciliten a terceras personas el acceso, distribuyan, difundan o vendan escritos o cualquier otra clase de material o soportes que por su contenido sean idóneos para fomentar, promover, o incitar directamente al odio contra un grupo o parte del mismo, o contra una persona determinada por razón de su pertenencia a aquél,”

2) Serán castigados con la pena de prisión de seis meses a dos años y multa de seis a doce meses:

a) Quienes lesionen la dignidad de las personas mediante acciones que entrañen humillación, menosprecio o descrédito de alguno de los grupos a que se refiere el apartado anterior, o de una parte de los mismos (...) o produzcan, elaboren, posean con la finalidad de distribuir, faciliten a terceras personas el acceso, distribuyan, difundan o vendan escritos o cualquier otra clase de material o soportes que por su contenido sean idóneos para lesionar la dignidad de las personas por representar una grave humillación, menosprecio o descrédito de alguno de los grupos mencionados, de una parte de ellos, o de cualquier persona determinada por razón de su pertenencia a los mismos.

b) Quienes enaltezcan o justifiquen por cualquier medio de expresión pública o de difusión los delitos que hubieran sido cometidos contra un grupo, una parte del mismo, o contra una persona determinada por razón de su pertenencia a aquél (...) Los hechos serán castigados con una pena de uno a cuatro años de prisión y multa de seis a doce meses cuando de ese modo se promueva o favorezca un clima de violencia, hostilidad, odio o discriminación contra los mencionados grupos.

Entre las novedades más significativas de la reforma de 2015, cabe señalar el agravamiento de las penas previsto en el art. 510.3 cuando los hechos se hubieran llevado a cabo a través de un medio de comunicación social, por medio de internet o mediante el uso de tecnologías de la información, de modo que, aquel se hiciera accesible a un elevado número de personas ${ }^{52}$. Igualmente se prevé una elevación de las penas "cuando los hechos, a la vista de sus circunstancias, resulten idóneos para alterar la paz pública o crear un grave sentimiento de inseguridad o temor entre los integrantes del grupo" (art. 510.4) En todos los casos se impondrá, además, la pena de inhabilitación especial para profesión u oficio educativos, en el ámbito docente, deportivo y de tiempo libre, por un tiempo superior entre tres y diez años al de la duración de la pena de privación de libertad impuesta en su caso en la sentencia, atendiendo proporcionalmente a la gravedad del delito, al número de los cometidos y a las circunstan-

52 Además, el legislador ha previsto que "El juez o tribunal acordará la destrucción, borrado o inutilización de los libros, archivos, documentos, artículos y cualquier clase de soporte objeto del delito a que se refieren los apartados anteriores o por medio de los cuales se hubiera cometido. Cuando el delito se hubiera cometido a través de tecnologías de la información y la comunicación, se acordará la retirada de los contenidos. En los casos en los que, a través de un portal de acceso a internet o servicio de la sociedad de la información, se difundan exclusiva o preponderantemente los contenidos a que se refiere el apartado anterior, se ordenará el bloqueo del acceso o la interrupción de la prestación del mismo." (art. 510.6). 
cias que concurran en el delincuente (art. 510.5).

La reforma también ha precisado los términos en que se entiende que constituye una acción discriminatoria la denegación de un servicio público (artículo 511.1) y de un servicio privado (artículo 512), así como la extensión de la ilicitud de las asociaciones a "las que fomenten, promuevan o inciten directa o indirectamente al odio, hostilidad, discriminación o violencia contra personas, grupos o asociaciones..." (artículo 515).

Además de los avances introducidos en el Código Penal, una de las novedades más significativas de los últimos años en España ha sido la creación en la Fiscalía de un servicio especializado de delitos de odio y discriminación. El primero de ellos se creó en 2009 en Cataluña gracias precisamente a la insistencia de los colectivos en LGTBI en tener un interlocutor. Posteriormente se crearon servicios análogos en Madrid y Málaga. Mediante Decreto de 10 de octubre de 2011 el Fiscal General del Estado nombró un Fiscal Delegado para la tutela penal de la igualdad y contra la discriminación, con el objetivo de que nombrara los fiscales delegados en cada provincia y coordinara su actuación. En 2013 fueron nombrados 50 fiscales delegados, uno por cada provincia.

\section{ANEXO 2: Entrevista a especialistas, coordinadores y promotores de la Sección Provincial del Programa ITS-VIH-SIDA y Hepatitis B y C, así como miembros LGBTI.}

Se solicita su colaboración en la investigación sobre la protección jurídico penal de la comunidad LGBTI en Cuba, que se desarrolla en el trabajo de diploma en opción al título de Licenciada en Derecho, en la Facultad de Ciencias Sociales y Humanísticas de la Universidad de Guantánamo, para ello se necesita que responda las siguientes interrogantes según su experiencia en la investigación y seguimiento del tema. Agradecemos su cooperación:

1) Según la realidad social que se vive y su experiencia en la responsabilidad que desempeña en el centro, ¿cuáles son las principales manifestaciones de discriminación que plantean los LGBTIQ que son atendidos?

2) ¿Qué nivel de respuestas reciben?

3) ¿Existe algún mecanismo para atender y dar respuesta a los actos discriminatorios?

4) ¿Se cuenta en el centro con datos en cifras de víctimas de violaciones a sus derechos, dígase lesiones, homicidios, asesinatos?

5) Experiencias personales sobre la discriminación sufrida como LGBTIQ

6) ¿Conoce usted cómo se protege la orientación sexual en el Código Penal cubano? 
ANEXO 3: Listado de los entrevistados.

\begin{tabular}{|c|c|c|c|}
\hline No. & Nombre y Apellidos & Profesión u oficio & Responsabilidad en la sección \\
\hline 1 & Aracelis Martín Téllez & Lic. en Educación & $\begin{array}{l}\text { Especialista del componente } \\
\text { educativo. }\end{array}$ \\
\hline 2 & Ibrahím Ramos Marín (HSH) & $\begin{array}{l}\text { Técnico Medio en } \\
\text { Cultura Física }\end{array}$ & $\begin{array}{l}\text { Coordinador de la Red HSH- } \\
\text { Cuba. Educador del programa } \\
\text { ITS-VIH-SIDA. Mcpio. Gtmo. }\end{array}$ \\
\hline 3 & Ángel Vargas Díaz (HSH) & $\begin{array}{l}\text { Técnico Medio en } \\
\text { Informática }\end{array}$ & Coordinador de la línea PPST \\
\hline 4 & $\begin{array}{l}\text { Reynaldo Enrique Veiries } \\
\text { Hinojosa (Trans) }\end{array}$ & - & Promotor del Proyecto Trans \\
\hline 5 & $\begin{array}{l}\text { Charles Ariano Toirac } \\
\text { (HSH) }\end{array}$ & $\begin{array}{l}\text { Estudiante 1ro } \\
\text { Medicina }\end{array}$ & Promotor del centro \\
\hline 6 & $\begin{array}{l}\text { Erislandis García Fernández } \\
\text { (HSH) }\end{array}$ & $\begin{array}{l}\text { Lic. Rehabilitación } \\
\text { y Podología }\end{array}$ & Promotor del centro \\
\hline 7 & $\begin{array}{l}\text { Carlos Raciel Morenza } \\
\text { Vázquez (Trans) }\end{array}$ & Lic. Economía & $\begin{array}{l}\text { Coordinador de la Red Trans por } \\
\text { el CENESEX }\end{array}$ \\
\hline
\end{tabular}

ANEXO 4: Casos atendidos en los Servicios de Orientación Jurídica del CENESEX.

\begin{tabular}{|c|c|c|c|c|c|c|c|c|c|}
\hline $\begin{array}{l}\text { Cantidad } \\
\text { de casos } \\
\text { atendidos }\end{array}$ & $\begin{array}{c}\text { Discriminación } \\
\text { en el ámbito } \\
\text { laboral }\end{array}$ & $\begin{array}{c}\text { Quejas y/o } \\
\text { inconformidad } \\
\text { sobre procesos } \\
\text { penales }\end{array}$ & Civil & $\begin{array}{c}\text { Quejas } \\
\text { sobre } \\
\text { viviendas }\end{array}$ & $\begin{array}{c}\text { Discriminación por } \\
\text { orientación sexual } \\
\text { e identidad de } \\
\text { género en otros } \\
\text { ámbitos }\end{array}$ & $\begin{array}{c}\text { Discriminación } \\
\text { en el ámbito } \\
\text { familiar }\end{array}$ & $\begin{array}{c}\text { Cambio } \\
\text { de } \\
\text { nombres }\end{array}$ & $\begin{array}{c}\text { Servicios } \\
\text { comunales }\end{array}$ & Otros \\
\hline 335 & 48 & 72 & 36 & 92 & 49 & 16 & 3 & 1 & 38 \\
\hline
\end{tabular}

Fuente: Información tomada del artículo, "Derechos sexuales y violencia de género: algunas aproximaciones a la problemática de la violencia de género hacia personas LGBTIQ en Cuba", Revista Sexología y Sociedad, Edit. CENESEX, No. 55, Junio de 2017 del Ms.C Manuel Vázquez Seijido. 


\section{ANEXO 5: Estudio exploratorio realizado en el país por el CENESEX.}

Como parte de un estudio exploratorio del CENESEX sobre la violencia y la identidad de género por orientación sexual en Cuba, se formuló una encuesta para determinar factores victimógenos en personas LGBTI. Esta encuesta se aplicó a 106 personas, en el marco de talleres, reuniones y encuentros sostenidos por las redes que integran las Redes Sociales Comunitarias del Centro Nacional de Educación Sexual.

Respondieron la encuesta 71 personas que se identificaban como trans, 19 hombres gays y $16 \mathrm{mu}$ jeres lesbianas o bisexuales, procedían de 12 provincias del país.

\begin{tabular}{|l|l|}
\hline Provincias & $\begin{array}{l}\text { Cantidad de personas } \\
\text { encuestadas }\end{array}$ \\
\hline Granma & 25 \\
\hline La Habana & 24 \\
\hline Matanzas & 18 \\
\hline Pinar del Río & 9 \\
\hline Santiago de Cuba & 6 \\
\hline Guantánamo & 6 \\
\hline Holguín & 6 \\
\hline Las Tunas & 5 \\
\hline Cienfuegos & 2 \\
\hline Artemisa & 2 \\
\hline Mayabeque & 1 \\
\hline Santa Clara & 1 \\
\hline
\end{tabular}

Algunos resultados obtenidos: Problemáticas de la violencia por orientación sexual hacia las mujeres lesbianas o bisexuales. La mayoría de ellas (8), han sido víctimas de la violencia asociada a su orientación sexual, resulta llamativo que dos de ellas no estaban seguras acerca de si habían sido víctimas, 10 de ellas no ofrecieron información sobre las características de las agresiones recibidas. Solo 4 declararon haber sufrido violencia verbal con implicaciones psicológicas y 3 informaron ser víctimas de violencia física y verbal, 10 de ellas no explicaron de quién procedía la violencia ejercida sobre ellas, mientras que el resto declaró que habían sido agredidas por oficiales de la PNR, por otras personas 3, e incluso por grupo de personas 2 . Al intentar explorar la reacción o respuestas ante las agresiones recibidas, la mayoría (9) no ofreció información, el resto declaró que no hizo nada al respecto (5), que respondió con igual violencia 2, o que huyó 2 , solo 1 persona observó la posibilidad de denunciar lo sucedido. En este último caso, la atención por parte de las autoridades competentes para radicar la denuncia, fue 
negativa al identificar la víctima y restar importancia a su caso.

Problemáticas de la violencia por orientación sexual hacia hombres gays. La mayoría de los encuestados (14) declaró haber sido víctima de violencia, de ellos 11 aseguraron que el motivo era su orientación sexual homosexual. La violencia verbal con impacto en la estabilidad emocional prevaleció entre los hombres gays encuestados. Un total de 10 personas apuntan que han sufrido o están sufriendo insultos o amenazas. Solo 4 aseguraron haber sido víctimas de actos de violencia física. En este caso la violencia recibida se identificó en el seno familiar (3), por personas que no conocían (3), en menor medida por oficiales de la policía (1) y en la mayoría de los casos por personas solas(5) y por grupos de estas (4).

En cuanto a su respuesta o reacción por la violencia, la mayoría (7) aceptaron que no hicieron nada ante la ocurrencia de este tipo de eventos, mientras que otro grupo (4) aceptó que huía ante estos acontecimientos. La minoría decidió denunciar (2) o responder con violencia (2), quienes informaron que habían denunciado, informaron de negativa la atención recibida por las autoridades competentes para radicar las denuncias, pues no prestaron la debida diligencia en estos casos.

Problemáticas de la violencia por orientación sexual hacia personas trans. Estas fueron la mayor cantidad de personas encuestadas, lo que obedece a que es la red con mayor número de activistas en todo el país, la mayoría de los trans encuestados (63) declararon que fueron víctimas de violencia, de ellos 43 afirmaron que estos actos de violencia eran motivados por su identidad de género. Solo 9 personas informaron que no habían experimentado ninguna manifestación de violencia. Aunque 10 personas trans no respondieron sobre el tipo de violencia recibida, la mayoría (32) afirmó que habían sido víctimas solo de violencia verbal (insultos y amenazas), mientras que 28 personas declararon que habían sido víctimas de violencia física y verbal (puñetazos, heridas con armas blancas o de fuego, pedradas...). Solo 1 persona declaró que había recibido únicamente violencia física.

De las personas encuestadas, la mayoría informó que había sido violentada por oficiales de la policía (29), también por otras personas 28 o grupo de estas 23, así como sus parejas (17) y familiares (11). Otro grupo (26) también refirió que había recibido violencia por personas totalmente desconocidas. Con relación a su respuesta la mayoría aceptó responder con igual violencia, complejizándose más el tema. Otro número declaró no hacía absolutamente nada o que huía, y en menor medida que habían denunciado el hecho. De manera coincidente con los otros grupos encuestados, la atención recibida por parte de las autoridades no fue positiva.

Fuente: Información tomada del artículo, "Derechos sexuales y violencia de género: algunas aproximaciones a la problemática de la violencia de género hacia personas LGBTIQ en Cuba”, Revista Sexología y Sociedad, Edit. CENESEX, No. 55, Junio de 2017, del Ms.C Manuel Vázquez Seijido. 